\title{
A rare case of chronic myeloid leukemia with secondary chromosomal changes including partial trisomy 17q21 to 17qter and partial monosomy of $16 \mathrm{p} 13.3$
}

Walid Al Achkar ${ }^{1 *}$, Abdulsamad Wafa ${ }^{1}$, Hasmik Mkrtchyan ${ }^{2,3}$, Faten Moassass ${ }^{1}$, Thomas Liehr ${ }^{2}$

\begin{abstract}
Background: The so-called Philadelphia (Ph) chromosome is present in almost all cases with chronic myeloid leukemia (CML). Around 5-10\% of these patients show complex translocations involving other chromosomes in addition to and/or besides chromosomes 9 and 22. As nowadays most CML cases are treated with Imatinib, variant rearrangements have in general no specific prognostic significance, though events of therapy resistance remain to be studied.

Results: Here we report a Ph chromosome positive patient with hematological typical chronic phase CML. Untypically, an unbalanced complex rearrangement involving chromosomes 16 and 17 leading to a deletion of 16pter and partial trisomy of 17q21 to 17qter, was identified besides a trisomy 8 and an additional Ph chromosome in a part of malignant cells.

Conclusion: Here a novel and cytogenetically unique case of a Ph chromosome positive CML clinically in chronic phase is reported, having complex secondary chromosomal aberrations. Thus, CML patients with complex chromosomal changes are nonetheless treatable by Imatinib.
\end{abstract}

\section{Background}

Chronic myeloid leukemia (CML) is a clonal malignant disorder of a pluripotent hematopoetic stem cell characterized by the presence of the Philadelphia $(\mathrm{Ph})$ chromosome in more than $90 \%$ of patients. The Ph chromosome is a product of the reciprocal translocation $\mathrm{t}(9 ; 22)(\mathrm{q} 34$; q11), which transposes the 3' portion of the ABL oncogene from 9q34 to the 5' portion of the BCR gene on 22q11.2. The crucial pathogenetic consequence of this translocation is the creation of a chimeric $\mathrm{BCR} / \mathrm{ABL}$ gene on the derivative chromosome 22 [1]. The expression of the $\mathrm{BCR} / \mathrm{ABL}$ chimeric protein with an increased tyrosine kinase activity plays an essential role in the pathogenesis of CML [2].

The progression of CML from chronic phase (CP) to blast crisis $(\mathrm{BC})$ is frequently associated with nonrandom

\footnotetext{
* Correspondence: scientific@aec.org.sy

${ }^{1}$ Molecular Biology and Biotechnology Department, Human Genetics Division, Atomic Energy Commission, Damascus, Syria
}

secondary chromosomal aberrations such as $+8, \mathrm{i}(17 \mathrm{q})$, +19 and an extra Ph chromosome [3]. Imatinib mesylate (Glivec, formerly STI571) was designed specifically to inhibit the tyrosine kinase activity of the $\mathrm{BCR} / \mathrm{ABL}$ protein and other tyrosine kinases such as cABL, c-KIT and PDGF (platelet-derived growth factor receptor). By binding to an active site of the tyrosine kinase, Glivec switches off downstream signaling, cells stop proliferating and apoptosis ensues [4]. Many studies have shown a high efficiency of Imatinib therapy to achieve a complete or major cytogenetic response, i.e. a reduction to $0-34 \%$ Ph-positive cells. This positive effect may be attained in cases with a simple $t(9 ; 22)$, in such with complex translocations resulting in a $\mathrm{BCR} / \mathrm{ABL}$ fusion gene, as well as in cases with cytogenetic clonal evolution $[5,6]$.

Herein we report a rare case of a $\mathrm{Ph}$ chromosome positive CML with a derivative chromosome 16 leading to a partial trisomy $17 \mathrm{q} 21$ to 17 qter and partial deletion of 16 pter, which was nonetheless successfully treatable by Imatinib. 


\section{Case report}

A 30-year old male was diagnosed to suffer from CML in $\mathrm{CP}$ after a blood cell count was initiated in June 2009 due to splenomegaly and severe loss of weight. The patient was treated with Imatinib mesylate at a $400 \mathrm{mg}$ /day for overall 12 months and previous relevant symptoms disappeared. Hematologic parameters were as follows: hemoglobin $129 \mathrm{~g} / \mathrm{l}$; platelets count was $103 \times 10^{9} / \mathrm{l}$; and white blood cells (WBC), $5 \times 10^{9} / 1$ with $57.2 \%$ neutrophils, $36.3 \%$ lymphocytes, $4.8 \%$ monocytes, $1.3 \%$ eosinophiles and $0.4 \%$ basophiles.

Karyotyping was done after initiation of chemotherapy treatment, showing the following karyotypic changes. A complex karyotype $48, \mathrm{XY},+8, \mathrm{t}(9 ; 22)$ (q34;q11), $\operatorname{der}(16)$, $\mathrm{t}(16 ; 17),+\operatorname{der}(22) / 47, \mathrm{XY},+8, \mathrm{t}(9 ; 22)(\mathrm{q} 34 ; \mathrm{q} 11), \operatorname{der}(16)$, $\mathrm{t}(16 ; 17) / 46, \mathrm{XY}, \mathrm{t}(9 ; 22)(\mathrm{q} 34 ; \mathrm{q} 11)$ was determined in GTGbanding (Fig. 1) and further specified by molecular cytogenetic studies (Fig. 2, 3). Dual-color-FISH using a probe specific for BCR and ABL revealed a typical Philadelphia-chromosome with BCR/ABL fusion gene was present and the second derivative chromosome 22 was a second $\mathrm{Ph}$ chromosome (Fig. 2). M-FISH, was applied to exclude further cryptic rearrangements (Fig. 3A). As no other additional changes were found by that approach, array-proven high-resolution multicolor banding (aMCB) (10) probe sets for chromosomes 16 and 17 were applied. Thus, an intrachromosomal rearrangement on the derivative chromosome 16 was detected additionally to the translocation of chromosome 17 material to the derivative chromosome 16 (Figs. 3B and 3C). Finally, a subtelomeric probe for 16pter revealed a partial deletion on the derivative chromosome 16 (Fig. 3D). Thus, the following final karyotype was obtained: $48, \mathrm{XY},+8$, $\mathrm{t}(9 ; 22)$ (q34;q11), der(16)t(16;17)(16qter $\rightarrow 16 \mathrm{q} 22:: 16 \mathrm{p} 13.3 \rightarrow$ $16 q 22:: 17 q 21 \rightarrow q$ ter $),+\operatorname{der}(22) t(9 ; 22)(q 34 ; q 11)[8] / 47$,

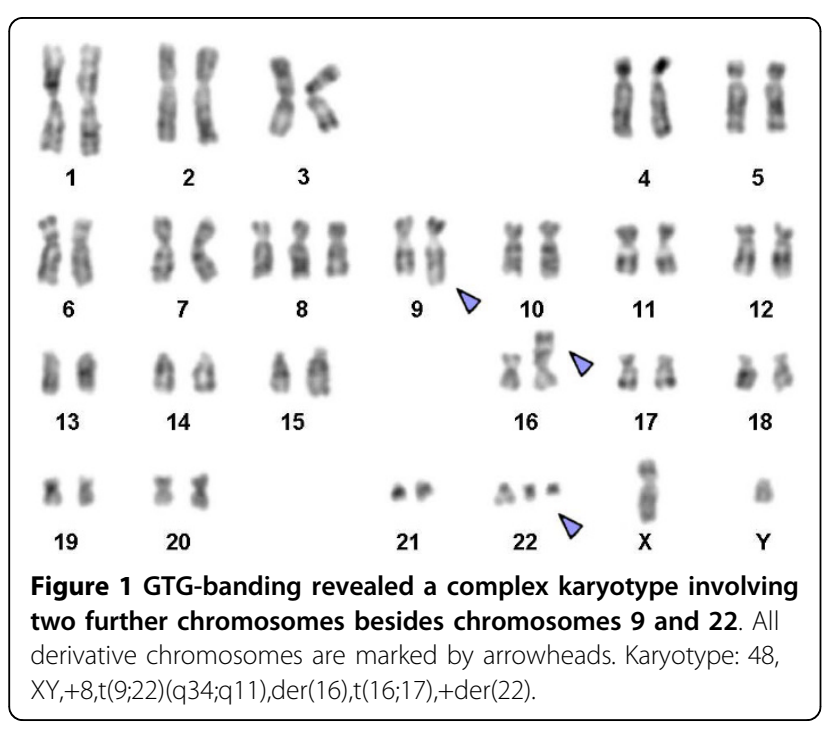

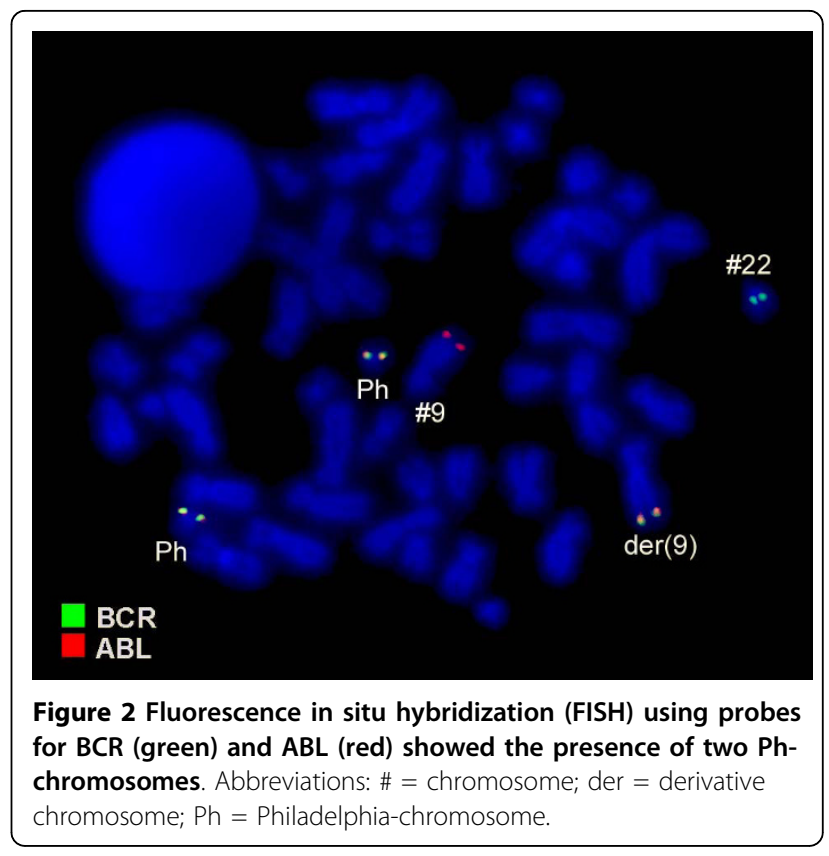

$\mathrm{XY},+8, \mathrm{t}(9 ; 22)(\mathrm{q} 34 ; \mathrm{q} 11), \operatorname{der}(16) \mathrm{t}(16 ; 17)(16 \mathrm{qter} \rightarrow 16 \mathrm{q} 22::$ $16 \mathrm{p} 13.3 \rightarrow 16 \mathrm{q} 22:: 17 \mathrm{q} 21 \rightarrow \mathrm{qter})[8] / 46, \mathrm{XY}, \mathrm{t}(9 ; 22)(\mathrm{q} 34 ; \mathrm{q} 11)$ [4].

\section{Discussion}

In a case of a $\mathrm{CP} \mathrm{Ph}$ chromosome positive CML additional chromosomal changes were detected. Apart from a trisomy 8 and an additional derivative chromosome 22 two additional chromosomal alterations were present: an intrachromosomal rearrangement involving 16q22, 16 p11.3 and an interchromosomal one with breakpoints in $16 \mathrm{q} 22$ and $17 \mathrm{q} 21$. To our knowledge, this translocation has been never observed in CML before [7].

In $5-10 \%$ Ph chromosome CML cases have complex translocations in addition to those and/or besides chromosomes 9 and 22 [1]. At present it appears that in such rearrangements any other chromosome may be involved. However, it has been suggested that distribution of chromosomes and breakpoints is non-random with the chromosomal bands most susceptible to breakage being 1p36, 3p21, 5q31, 6p21, 9q22, 10q22, 11q13, 12p13, 17p13, 17q21, 17q25, 19q13, 21q22, 22q12 and 22q13 [8], showing one match with the present case, i.e. $17 \mathrm{q} 21$.

Additionally, the two breakpoints in chromosome 16 have previously been reported to be associated with acute nonlymphocytic leukemia (ANLL) type M4 [9]. 16q22 is frequently found in the ANLL typical inversion (16) (p13q22) and the related interchromosomal translocation (16;16)(p13;q22). These chromosome 16 rearrangements resulted in the disruption of the myosin heavy chain (MYH11) gene mapping to chromosome 16p13.13 to $16 \mathrm{p} 13.12$ [10]. MYH11 encodes the smooth-muscle 

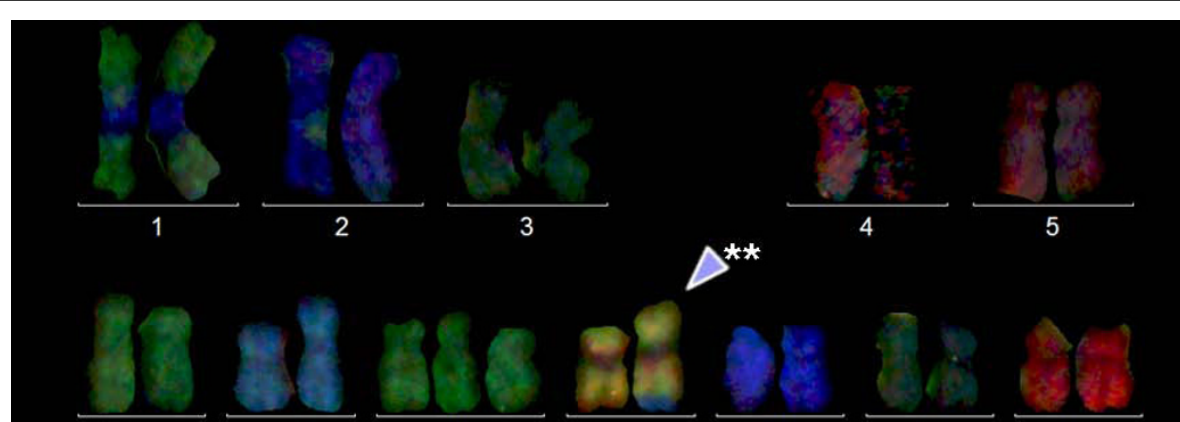

5
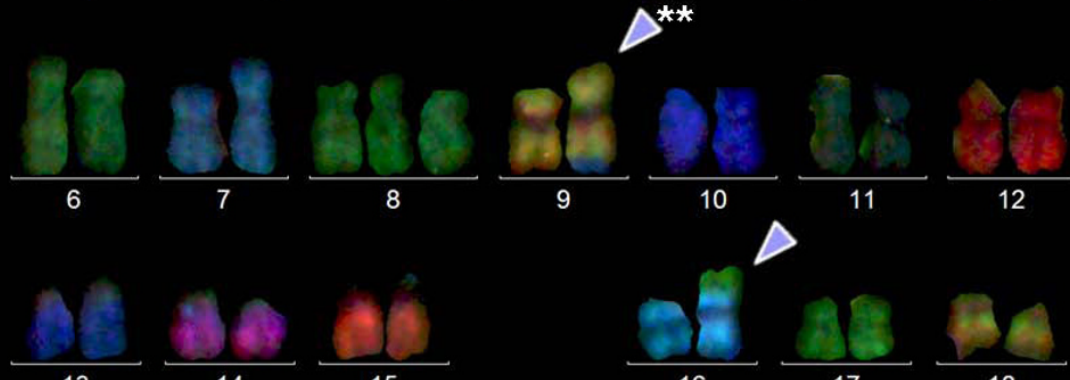

15
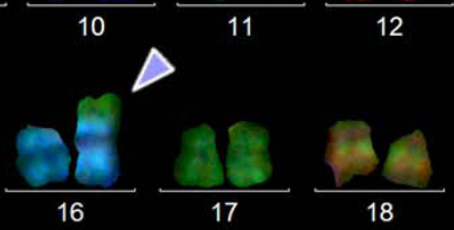

18
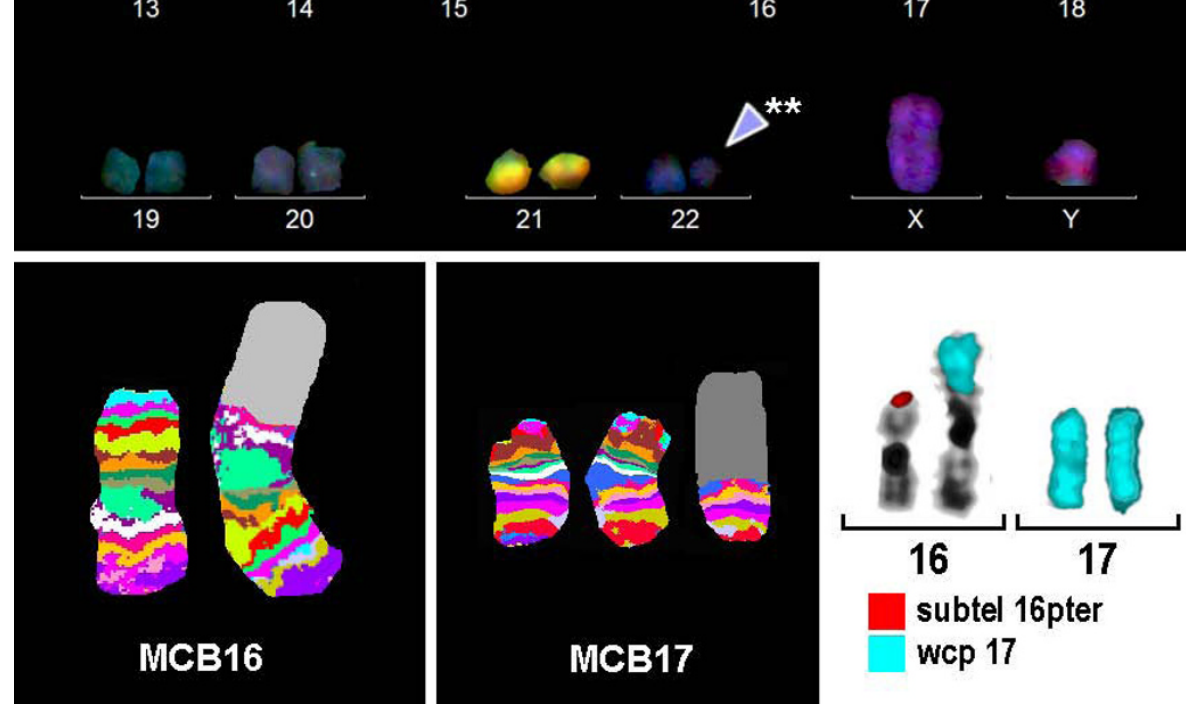

16

17

subtel 16pter

wcp 17

Figure 3 Karyotype and chromosomal aberrations were confirmed using molecular cytogenetic approaches. (A) M-FISH confirmed the complexity of the karyotype: $47, X Y, t(9 ; 22)$,der(16)t(16;17), +8 . (B) and (C) The application of MCB 16 and 17 revealed the chromosomal breakpoints on the corresponding derivative chromosomes as 16p13.3 and 16 q22 and 17q21. (D) The deletion of the subtelomeric region on the der(16)

and the translocation of chromosome 17 material was also demonstrated by the application of a subtelomeric probe for 16p (Abbott Molecular/ Vysis, USA) and a whole chromosome painting (wcp) probe for chromosome 17.

myosin heavy chain and belongs to the family of conventional myosins. The well-characterized biological function of myosins is their ability to use the energy of ATP hydrolysis to move actin filaments and produce muscle force. Recently, myosins have been implicated in a variety of other intra-cellular functions, including cell migration, adhesion, control of cell shape, and membrane traffic but are implicated also in a variety of other cellular functions, many of which are relevant for cancer formation [11]. Unfortunately, in the present case no material was available to test if MYH11 was involved in the rearrangement.

During CML progression trisomy of chromosomes 8 and a second $\mathrm{Ph}$ chromosome are frequent anomalies in CML [3]. Also, another leukemogenic effect of the der(16) may be due to increase copy number of the 17 q21 to 17 qter region. Morerio et al. [12] have reported that trisomies for this region represent a negative prognostic indicator in myeloid neoplasia. Also an isochromosome $17 \mathrm{q}$ is a well-known progression step in CML.

In conclusion, here we reported a novel and cytogenetically unique case of a $\mathrm{Ph}$ chromosome positive CML in $\mathrm{CP}$. Especially the latter fact being still a CML in $\mathrm{CP}$ and not in $\mathrm{BC}$ when having such complex secondary chromosomal aberrations is intriguing. We suggest that the reported patient had nonetheless such a good response to Imatinib as irrespective of complex 
chromosomal changes he was treated 'just in time' before further mutations appeared leading to $\mathrm{BC}$.

\section{Materials and methods Chromosome analysis}

Chromosome analysis using GTG-banding was done according to standard procedures [13]. 20 metaphases analyzed from unstimulated bone marrow culture were analyzed. Karyotypes were described according to the International System for Human Cytogenetic Nomenclature [14].

\section{Molecular cytogenetics}

Fluorescence in situ hybridization (FISH) using LSI $\mathrm{BCR} / \mathrm{ABL}$ dual color dual fusion translocation probe (Abbott molecular/Vysis, USA) and subtelomeric probe for 16pter (Abbott molecular/Vysis, USA) were applied according to manufacturer's instructions together with a whole chromosome painting (WCP) probe for chromosome 17 [15]. Array-proven multicolor banding probe $(\mathrm{aMCB})$ sets based on microdissection derived regionspecific libraries for chromosome 16 and 17 were applied as described [16] 20 metaphase spreads were analyzed, each using a fluorescence microscope (AxioImager.Z1 mot, Zeiss) equipped with appropriate filter sets to discriminate between a maximum of five fluorochromes and the counterstain DAPI (Diaminophenylindol). Image capturing and processing were carried out using an ISIS imaging system (MetaSystems, Altlussheim, Germany) for the evaluation aMCB.

\section{Consent}

Written informed consent was obtained from the patient for publication of this case report and accompanying images. A copy of the written consent is available for review by the Editor-in-Chief of this journal.

\section{Acknowledgements}

We thank Dr. I. Othman, the Director General of Atomic Energy Commission of SYRIA (AECS) and Dr. N. Mirali, Head of Molecular Biology and Biotechnology Department for their support. This work was supported by the AECS, in parts by the Stefan-Morsch-Stiftung, Monika-Kutzner-Stiftung and the DAAD (D/07/09624).

\section{Author details \\ ${ }^{1}$ Molecular Biology and Biotechnology Department, Human Genetics Division, Atomic Energy Commission, Damascus, Syria. ${ }^{2} J e n a$ University Hospital, Institute of Human Genetics and Anthropology, Jena, Germany. ${ }^{3}$ Department of Genetic and Laboratory of Cytogenetics, State University, Yerevan, Armenia.}

\section{Authors' contributions}

AW and FM performed the cytogenetic studies in the present case and collected the data relative to this case report. WA supervised the cytogenetic analysis as Director of the HGD. HM, AW, FM TL did the molecular cytogenetic analysis and interpretation. TL drafted the paper and all authors contributed to the finalizing of the manuscript and read and approved it also in its final version.

\section{Competing interests}

The authors declare that they have no competing interests.

Received: 28 January 2010 Accepted: 16 March 2010

Published: 16 March 2010

\section{References}

1. La Starza R, Testoni N, Lafage-Pochitaloff M, Ruggeri D, Ottaviani E, Perla G, Martelli MF, Marynen P, Mecucci C: Complex variant Philadelphia translocations involving the short arm of chromosome 6 in chronic myeloid leukemia. Haematologica 2002, 87:143-147.

2. Lugo T, Pendergast A, Müller A, Witte O: Tyrosine kinase activity and transformation potency of bcr-abl oncogene products. Science 1990 247:1079-1082.

3. Sandberg AA: The chromosomes in Human Cancer and leukemia. Elsevier Science, New York, 2 1990, 151-172.

4. Griffen J: The biology of signal transduction The biology of signal transduction inhibition: basic science to novel therapies. Semin Oncol 2001, 28:3-8.

5. Kantarjian H, Sawyers C, Hochhaus A, Guilhot F, Schiffer C, GambacortiPasserini C, Niederwieser D, Resta D, Capdeville R, Zoellner U, Talpaz M, Druker B, Goldman J, O'Brien SG, Russell N, Fischer T, Ottmann O, ConyMakhoul P, Facon T, Stone R, Miller C, Tallman M, Brown R, Schuster M, Loughran T, Gratwohl A, Mandelli F, Saglio G, Lazzarino M, Russo D, Baccarani M, Morra E, International STI571 CML Study Group: Hematologic and cytogenetic responses to imatinib mesylate in chronic myelogenous leukemia. N Engl J Med 2002, 346:645-652.

6. Cortes JE, Talpaz M, Giles F, O'Brien S, Rios MB, Shan J, Garcia-Manero G Faderl S, Thomas DA, Wierda W, Ferrajoli A, Jeha S, Kantarjian HM: Prognostic significance of cytogenetic clonal evolution in patients with chronic myelogenous leukemia on imatinib mesylate therapy. Blood 2003, 101:3794-3800.

7. Mitelman Database of Chromosome Aberrations in Cancer (2009). Mitelman F, Johansson B, Mertens F [http://cgap.nci.nih.gov/Chromosomes/ Mitelman].

8. Johansson B, Fioretos T, Mitelman F: Cytogenetic and molecular genetic evolution of chronic myeloid leukemia. Acta Haematol 2002, 107:76-94.

9. Liu P, Tarle SA, Hajra A, Claxton DF, Marlton P, Freedman M, Siciliano MJ, Collins FS: Fusion between transcription factor CBF beta/PEBP2 beta and a myosin heavy chain in acute myeloid leukemia. Science 1993, 261:1041-1044.

10. Deng Z, Liu P, Marlton P, Claxton DF, Lane S, Callen DF, Collins FS, Siciliano MJ: Smooth muscle myosin heavy chain locus (MYH11) maps to 16p13.13-p13.12 and establishes a new region of conserved synteny between human 16p and mouse 16. Genomics 1993, 18:156-159.

11. Krendel M, Mooseker MS: Myosins: tails (and heads) of functional diversity. Physiology (Bethesda) 2005, 20:239-251.

12. Morerio C, Russo I, Rosanda C, Rapella A, Leszl A, Basso G, Maserati E, Pasquali $F$, Panarello $C:$ 17q21-qter trisomy is an indicator of poor prognosis in acute myelogenous leukaemia. Cancer Genet Cytogenet 2001 124:12-15.

13. Claussen U, Michel S, Mühlig P, Westermann M, Grummt UW, KromeyerHauschild K, Liehr T: Demystifying chromosome preparation and the implications for the concept of chromosome condensation during mitosis. Cytogenet Genome Res 2002, 98:136-146.

14. Shaffer L, Slovak M, Cambell L, (eds): ISCN (2009): An International System for Human Cytogenetic Nomenclature. S. Karger, Basel 2009.

15. Liehr $\mathrm{T}$, Starke $\mathrm{H}$, Weise A, Lehrer $H$, Claussen U: Multicolor FISH probe sets and their applications. Histol Histopathol 2004, 19:229-237.

16. Liehr T, Heller A, Starke H, Rubtsov N, Trifonov V, Mrasek K, Weise A, Kuechler A, Claussen U: Microdissection based high resolution multicolor banding for all 24 human chromosomes. Int J Mol Med 2002, 9:335-339.

doi:10.1186/1755-8166-3-6

Cite this article as: Al Achkar et al:: A rare case of chronic myeloid leukemia with secondary chromosomal changes including partial trisomy $17 q 21$ to $17 q$ ter and partial monosomy of $16 p 13.3$. Molecular Cytogenetics 2010 3:6. 